\title{
Core dimensions of food-related lifestyle: A new instrument for measuring food involvement, innovativeness and responsibility
}

\author{
Authors \\ Karen Bruns $\varnothing$, Dawn Birch, Juliet Memery, Ágoston Temesi, Zoltán Lakner, Mark Lang, David \\ Dean \& Klaus G. Grunert
}

\begin{abstract}
Segmentation is crucial for targeting product development initiatives and marketing communication nationally as well as internationally. In this paper we use the Food Related Lifestyle instrument that has been applied in the food arena for many years as a 'stepping stone' to develop a contemporary, targeted and smaller version of the Food Related Lifestyle instrument, still following the original theoretical framework. In particular we focus on three dimensions that have proven to be of core value in segmentation: food involvement; food innovativeness; and, food responsibility. Based on data collection in six countries (DK, $A U, H U$, UK, USA and NZ) across two rounds from 2017 to 2019 (total $N=3396$ ), we propose a new core instrument consisting of 15 items that have been tested for cross-cultural validity. Next, we used these three dimensions for segmentation across the six countries by applying multi-level latent class analysis. A solution leading to five different segments could be identified; the foodies, the moderates, the adventurous, the uninvolved and the conservatives. The segments were profiled by means of Schwartz's ten value domains and measures of self-reported food-related behaviour to check for nomonological validity. We conclude that the 15 items were cross-culturally valid, could be used for segmentation across six countries, and that segment profiling by means of Schwartz values and behavioural items were in line with the theoretical background.
\end{abstract}




\section{Introduction}

Segmentation is an approach to deal with individual differences between food consumers, both in a commercial and a public policy context (Grunert, 2019). While the concept originally stems from marketing and is used in that context to manage differences in consumers' needs and wants when developing and marketing food products (Wedel \& Kamakura, 2012), it has likewise been adopted in public policy, based on the conviction that individual differences between consumers affect their likely reaction not only to products coming onto the market, but also to food labelling, public health campaigns, and other attempts to influence consumer behaviour for consumers' or society's good (e.g., Kazbare, van Trijp \& Eskildsen, 2010). It is difficult to address millions of consumers individually, but by grouping them into segments based on relevant similarities such segments can become the point of departure for measures aimed at influencing consumer behaviour.

Lifestyle has been a popular base for segmentation in consumer marketing, and in the food domain the food-related lifestyle (FRL) instrument, developed in the mid-1990s (Bruns $\varnothing, 1997$; Bruns $\varnothing$ \& Grunert, 1998; see also Grunert, Bruns $\varnothing$, Bredahl \& Bech, 2001), has been used in over a hundred studies aimed at consumer segmentation and the explanation and prediction of foodrelated behaviours. The FRL approach views lifestyle as a cognitive mediator between life values, i.e. basic end states that people regard as desirable, and perception of and behaviour towards concrete food-related objects. In other words, the food-related lifestyle concept is an attempt to capture the differences in how people view food and drink as a means by which to attain their basic life values.

Measurement of FRL has been based on a 69-item questionnaire instrument that measures lifestyle in 23 dimensions, grouped into five areas (purchasing motives, quality aspects, cooking methods, ways of shopping and consumption situations). It has been shown to have good measurement equivalence across cultural and national boundaries, at least in a Western context (Scholderer, Bruns $\varnothing$, Bredahl \& Grunert, 2004; Thøgersen, 2017), and the notion that lifestyle mediates between values and food-related behaviours has been empirically validated (Bruns $\varnothing$, Scholderer \& Grunert, 2004a; 2004b).

FRL has been applied in many different contexts and countries, sometimes using its full version of all 69 items, and sometimes selecting one or more scales from the complete instrument. A few examples of studies using the full instrument will be mentioned here. In an ambitious crosscultural study of sustainable food consumption within 10 European countries, Thøgersen (2017) showed that segments derived using the FRL significantly accounted for variation in meat and organic consumption as well as for variation in preferences for sustainable food product innovativeness. Lombardini, Migliore, Verneau, Schifani and Cembalo (2015) used the FRL to investigate preferences for local food in Italy and concluded that the instrument was suitable to 
distinguish between preferences in relation to local food and short supply chains. Szakály, Szente, Kövér, Polereczki and Szigeti (2012) applied the FRL to study consumer preferences for functional foods in Hungary. By using the $69 \mathrm{FRL}$ items, 5 segments were identified and profiled according to their functional food habits and results showed a significant relationship between lifestyle, health behavior and preference for functional foods. As a last example, Pèrez-Cueto et al. (2010) investigated relationships between the FRL dimensions and obesity in a study with data from Belgium, Denmark, Germany, Greece and Poland. Results showed that specific dimensions of FRL could be used as potential predictors of obesity.

As mentioned, other studies have used only part of the instrument. Only three examples will be mentioned. One study from Australia focusing on cooking skills and nutrition knowledge confidence applied items from the FRL to analyse household gatekeepers' influence and dietary preferences on health practices across Australia. Results showed that food-skills and nutrition knowledge could play a major part in household related food practices (Burton, Reid, Worsley \& Mavondo, 2017). Kim, Lee and Lee (2018) focused on convenience and home meal replacement in single households in South Korea and used 18 selected items from the FRL as a basis for deriving segments (utilitarians, health conscious utilitarians and variety seekers). They concluded that the segments could explain purchase frequencies for home meal replacement solutions and preferences for convenience. A third example is a study about food preparation time in Germany and Italy, where three segments were identified (quickies, foodies and indifferent). Here the study investigated willingness to pay for various products, and it showed that it was possible to link different segment profiles to preferences for time saving related to food preparation (Casini et al, 2019).

As can be seen from the previous examples, the FRL or parts of it have been applied successfully in many different contexts, providing valuable new insights into food related lifestyles and behaviours. Still we think there is a need for new developments for two main reasons. The first is technical: with 69 items covering 23 dimensions, the FRL is a complex instrument. When considering applying the FRL in the context of a larger study, where a range of other constructs need to be measured, the instrument has often been viewed as too complex in terms of both the number of questionnaire items and ensuing analysis (Grunert, 2019) - especially in light of the fact that the segmentation solutions resulting from an application of the FRL seem to mirror a much smaller set of underlying dimensions, as we will elaborate below. The second reason is substantial. The way in which people view food has changed markedly over the past decades. Aspects related to the ethics and sustainability of food production and consumption, which are much in focus today (e.g., Sarti, Danall \& Testa, 2018; Verain, Sijtsema \& Antonides, 2016), are mostly absent in the FRL instrument, mirroring the fact that such issues were much less centre stage at the time the instrument was developed. 
In this paper, we propose a new instrument. It retains the basic idea of lifestyle being a cognitive mediator between life values and concrete food-related behaviours. In contrast to the existing FRL we propose a core model measuring only three dimensions: food involvement, food innovativeness, and food responsibility. We argue that these three dimensions are often sufficient for a meaningful segmentation, and they can be supplemented by other aspects of lifestyle that can be picked from a list of potential add-on modules, resulting in a modular foodrelated lifestyle (MFRL) model. We present an instrument to measure the three dimensions, provide evidence for its reliability and cross-cultural measurement invariance, and apply it for a cross-national segmentation based on data from six countries. We profile these segments with data for both life values and food-related behaviour, providing a first test of the nomological validity of the new instrument.

\section{Conceptual approach}

The FRL is based on a means-end approach to lifestyle (Brunsø, Scholderer \& Grunert, 2004). Means-end theory argues that people seek out products and services not for their own sake, but because they believe them to lead to self-relevant consequences that in turn allow them to attain their life values (Gutman, 1982). The FRL adopts this basic thinking to obtain an understanding of the role that food has in the lives of people. Everyday observation suggests that the role of food in life differs between people. Everybody needs to eat, but not everybody is equally interested in food. For some people, food just seems to be a necessity, with other aspects of life holding greater importance. For other people, food is enormously important, and they spend considerable resources in terms of both time and money on buying food, preparing meals, eating at home and dining out. In terms of the means-end approach, this suggests that, for some people, food has a major role in achieving their life values, whereas other people try to attain their central life values via other domains of life, not food. People not only differ in the degree of their involvement with food (Bell \& Marshall, 2003), they also differ in the reasons for the degree of involvement that they have with food. Most notably, some people use food to create stability and safety, whereas for others it is a way to express creativity and achieve self-fulfilment. There is therefore also considerable difference in relation to people's willingness to try new things in relation to food and in the kitchen. Thus a number of items in the developed FRL instrument also covered this dimension with inspiration from, among other scales, the Food Neophobia Scale (Pliner \& Hobden, 1992). In FRL the focus was on relating innovation to the means-end approach via several dimensions including shopping, meal preparation and eating, which make for a broader approach to the construct of innovation.

In trying to capture these differences, the FRL defined 23 dimensions in five areas: the motives linked to food purchases (which can be viewed as domain-specific adaptations of general life 
values), the type of food quality people seek, how they shop, how they cook and how they organise their meals. Using these dimensions as inputs, cluster analysis produced five generic types of segments (Grunert, Brunsø, Bredahl \& Bech, 2001): an adventurous segment characterised by demand for quality, having fun in the kitchen, enjoying new products and meals, and being motivated by the social and self-enhancing aspects of food, a conservative segment characterised by denouncing innovation in food products and meals, a conservative approach to cooking, and a demand for quality products, an uninvolved segment not caring much about anything regarding food and a high incidence of snacking and convenience food, a careless segment much like the uninvolved, but with an interest in new products and snacks, and finally a rational segment with moderate scores on most dimensions, but an above average interest in health and product information. This pattern has appeared, with slight variations, in a range of studies in different national contexts.

Grunert (2020) suggests the gist of the segment differences can be mapped onto just two underlying dimensions: the degree of food involvement (high for the adventurous and the conservative, low for the uninvolved and the careless, medium for the rational) and tradition vs. innovation in food (innovative for the adventurous and careless, traditional for the conservative and uninvolved, and moderate for the rational).

We therefore propose to develop an instrument that measures these two dimensions - food involvement and food innovativeness - directly, and to add a third dimension, food responsibility, to account for the recent heightened interest in the ethics and sustainability of food. We cover food responsibility in a summary way here, not distinguishing between different aspects of responsibility like ethics and environmental impac, tand this dimension can be supplemented by add-on modules to further explore various more specific themes of responsibility. We believe that these three dimensions will be enough for a basic segmentation of consumers according to their food-related lifestyle, in line with the results of the original instrument. These three basic dimensions can be supplemented by other more specific aspects characterising the meal production chain (planning and shopping, product quality, transport and storage, preparation and consumption), and a set of scales measuring these aspects is currently under development (not discussed in this paper). The aim is therefore to arrive at a modular approach to measuring foodrelated lifestyle, consisting of three core dimensions and a number of add-on dimensions that can be invoked depending on the aim of the study at hand.

As we retain the original means-end approach to lifestyle, the three core dimensions should mediate between life values and food-related behaviours. The proposed model is shown in Figure 1.

In this paper, we only address the development of the three core dimensions of the modular food related lifestyle model (Core MFRL). 


\section{Methodology}

\subsection{Data collection}

Data from six countries $(\mathrm{N}=3,396)$ were collected in two separate rounds from 2017 to early 2019. The first data collection (2017) included Denmark $(n=508)$, Hungary $(n=500)$ and Australia $(n=505)$, while the second round (2018/2019) was designed to validate scales and modules from the first round, and included the United States $(n=809)$, United Kingdom $(n=548)$ and New Zealand $(n=526)$.

Data was collected by programming the questionnaire in Qualtrics and using commercial online panels in all countries except for Hungary, where the survey was completed face-to-face. All respondents were screened for being the main grocery shopper in the household and being aged 18 years or above. In addition, in the Danish sample an equal gender split of the sample was enforced. In Australia, a distribution across states of residence that corresponds to the national distribution was enforced. Also in the USA the geographical distribution of respondents was enforced for representativeness.

In Hungary the sample was collected face to face and was designed to be proportionate in relation to regions as well as to city/settlement sizes across Hungary. The interviews were completed using a strictly specified random walk procedure with defined starting points and directions for which household to approach next.

\subsection{Measures}

The questionnaire used was identical in the six countries of the study with the exceptions noted below. The master questionnaire was developed in English and then translated into Danish and Hungarian and back translated for validity checking.

Twenty-five items were compiled to measure the three dimensions of food involvement, food innovativeness and, food responsibility. These were partly drawn from the FRL instrument, and partly newly developed to reflect contemporary issues. Measures for these 25 items were obtained in the Danish sample. A series of exploratory factor analyses were carried out to find those 5 items that worked best as indicators for each of the three constructs of food involvement, food innovativeness and, food responsibility. These 15 items were included in the questionnaire used in the remaining five countries. All items were answered using a 7-point scale with ends labelled $1=$ completely disagree and $7=$ completely agree. The items can be seen in Table 2 . 
For segment profiling and validation, life values were measured using the PVQ-21 instrument that measures Schwartz's (1992) ten value domains through 21 items (Bilsky, Janik \& Schwartz, 2011) (these measures were not included in the Australian and Hungarian samples). These items were answered on the original 6-point scale ranging from 1=not at all like me to $6=$ very much like me. Based on the items, scores were computed for the ten Schwartz value domains as means of the items measuring that particular domain.

Self-reported food-related behaviour was measured using 32 items assessing frequency of a) using different types of stores, b) consuming different types of products, c) using extended time for cooking and baking and, d) having different types of meals. These were partly composed of items used earlier in the validation of the FRL instrument (Bruns $\varnothing$, Scholderer \& Grunert, 2004a) and partly newly developed items. Responses were recorded on a frequency scale $1=$ never, 2=less than every 6 months, 3=1-5 times every 6 months, 4=1-3 times every month, 5=1-2 times per week, 6=3-4 times per week, 7=every day or almost every day.

The questionnaire included measures of demographic characteristics. In addition, the questionnaire contained 101 items measuring a range of possible add-on dimensions to the three core dimensions. Results of these are not reported in this paper.

\subsection{Analysis}

The factor structure of the 15 items measuring food involvement, food innovativeness and, food responsibility was ascertained using confirmatory factor analysis. Cross-cultural validity was checked by comparing the fit of the models for different levels of measurement invariance using multi-sample confirmatory factor analysis as proposed by Dimitrov (2010) and Steenkamp and Baumgartner (1998). These analyses were carried out in AMOS 25.

Segmentation based on the 15 items was carried out as a multi-level cluster analysis in LatentGold 5.1 (Vermunt \& Magidson, 2013). Country was used as the higher-order grouping factor. The resulting segments and country groups were then profiled using the scores for Schwartz value domains and for the self-reported behaviour. Significance of differences between the segments were analysed using ANOVA. These analyses were carried out in SPSS 26.

\section{Results}

\subsection{Factor structure and cross-cultural measurement invariance}

In order to check for cross-cultural measurement equivalence, a multi-sample confirmatory factor analysis was carried out for five levels of measurement invariance: configural invariance 
(pattern of loadings identical across countries), metric invariance (equal factor loadings across countries), scalar invariance (also equal intercepts across countries), factor covariance and variance invariance (also factor variances and co-variances equal across countries), and error invariance (also error variances equal across countries). Fit measures for the five models for all six countries can be seen in Table 2 . The results show very good fit measures across all levels, indicating a high degree of cross-cultural measurement invariance across the six countries. Loadings of the 15 items on the three underlying dimensions can likewise be seen in Table 2.

\subsection{Multi-level cluster analysis}

In order to identify a clustering solution, 36 models were estimated with the number of clusters varying between 1 and 6 and number of country groups likewise varying between 1 and 6 . Cluster solutions were compared using the Bayesian Information Criterion based on the log-likelihood (BIC-LL), which are shown for all 36 models in Table 3. The table shows that the BIC-LL reaches its lowest value for a solution with 5 clusters and 3 country groups.

Table 4 shows cluster sizes and means for the three dimensions for country groups and clusters. Country group 1 comprises Australia, New Zealand and the USA. Country group 2 comprises Denmark and the UK. Country group 3 consists only of Hungary. Comparison of the means of the three dimensions for the clusters shows that there are two main segments and three smaller segments. Of the two main segments, one has average values on all three dimensions and is hence called the moderates. The other main segment has higher mean values on all three dimensions, but especially on innovativeness, and is, alluding to results from the FRL instrument called the adventurous segment. The first of the three smaller segments has low values on all three dimensions and is hence, again alluding to the FRL segments, called the uninvolved. Another small segment has very high values on all dimensions and is called foodies. Finally, there is a segment with relative high food involvement, but low innovativeness and lower responsibility. Again such a segment is well-known from the FRL instrument and is called the conservative segment.

\subsection{Segment profiling}

Table 5 shows mean scores for the 10 Schwartz value domains for the segments. Results of ANOVAs show that there are significant differences between the segments for self-direction, stimulation, hedonism, security, tradition and conformity. The foodies score highly on selfdirection, stimulation and hedonism and low on security, tradition and conformity. The adventurous likewise score highly on self-direction and stimulation, but lower than the foodies. They also score low on conformity, but not on security and tradition. The moderates have medium level scores. The conservative segment scores low on stimulation, but high on hedonism, 
as well as high on security and conformity. Finally, the uninvolved score low on selfdetermination, stimulation and hedonism, and high on security, conformity and tradition.

In order to illustrate differences between the segments in terms of self-reported food-related behaviour, ANOVAs were carried out for the 32 items measuring self-reported frequency for shopping at different outlets, eating different products, spending time in the kitchen, and having different types of meals. The ANOVAs indicate significant differences between segments for all of the items except for one. Results are shown in Table 5. The largest differences are found for shopping in specialist stores and online, for eating fruits and vegetables, for spending time in the kitchen, and for eating dinner out at restaurants. Foodies shop most often online and at specialist stores. The adventurous and the conservative shop more often at specialist stores than the moderates and the uninvolved. Foodies eat fruits and vegetables most frequently, followed by the adventurous. Unsurprisingly foodies spend most frequently more than one hour in the kitchen, followed by the adventurous and the conservatives. Foodies also eat most frequently at restaurants, followed by the adventurous and the moderates, who do this more frequently than the conservatives and the uninvolved.

Analysis of demographic differences between segments showed no significant differences in gender composition of the segments. The foodies and adventurous segments are significantly younger and the conservative and uninvolved segments are significantly older, with the moderates being in between.

\section{Discussion}

In this paper we have described the development and validation of a new tool for segmenting consumers based on their food-related lifestyle. Retaining the original idea of the food-related lifestyle concept (Bruns $\varnothing$, Scholderer \& Grunert, 2004a), namely that lifestyle is viewed as a cognitive construct that mediates between life values and food-related behaviours, we developed an instrument that measures three core dimensions of food-related lifestyle: food involvement, food innovation, and food responsibility. Each dimension is measured by five items. The reliability of the measures and their cross-cultural measurement equivalence has been established by multigroup confirmatory factor analysis utilising data from six countries. A segmentation analysis based on data from these six countries yielded a solution with five segments, and profiling these segments with data on the endorsement of life values and on selfreported behaviour has validated the usefulness of these segments to explain how life values relate to food-related behaviours. 
While the new instrument retains the basic idea of the original Food-Related Lifestyle instrument, it has a number of advantages. First, with 15 items it is a considerably more practical and efficient instrument to use than the original tool with its 69 items. Second, the conceptual domains that it covers have been extended by the food responsibility dimension, taking into account the dramatic rise in importance topics related to food responsibility have attained in recent years. Third, our initial analysis using data from six countries suggests that the new instrument has better crosscultural validity than the original instrument, which had metric but not scalar invariance (Scholderer et al., 2004).

The instrument will be a useful tool to support marketing research, strategy, and tactical development, most notably segmentation, targeting, and positioning in the strategy process. It will be especially useful in new product development and in the design of social marketing interventions. The use of segmentation tools in new product development is firmly established (Creusen, Hultink \& Eling, 2013), but few ready-to-use methods have been available. Our tool can be used throughout the new product development process, starting with the generation of ideas with consumers pre-selected for segment membership, and continuing to concept and prototypetesting with segments at which the new product is targeted. The instrument will be equally useful for audience segmentation in the context of public health campaigns. Use of segmentation methods in social marketing interventions is relatively limited (Kubacki et al., 2017), and at least in the context of food-related interventions, the lack of a ready-to-use instrument may be one reason. Our instrument can be used for audience identification, for the co-creation of campaign content with selected segments, and for the measurement of effects with the intended audience.

\section{Conclusion}

As noted at the beginning of the paper, a key idea of the new tool is to combine a core instrument, consisting of measures for three core dimensions, with a number of add-on modules that can be selected according to purpose, such that segmentation solutions can be tailored to the specific needs of every application while still retaining the advantages of a standard and validated instrument. The three dimensions have been tested within and across countries and have in all respect shown to be individual dimensions not cofounding or overlapping in the themes they cover. The dimensions also confirm the role of food-related lifestyles as bridging betwee values and behaviour, as the segments derived from the analysis differ significantly in terms of both values and food related behaviour. Even though 6 countries have been the basis for the development of the new instrument, more studies in other countries should confirm further cross-cultural validity. The next step is the development and testing of add-on modules, and this is already underway and is a major focus for future research. 


\section{References}

Bell, R., \& Marshall, D. W. (2003). The construct of food involvement in behavioral research: scale

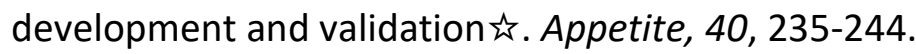

Bilsky, W., Janik, M., \& Schwartz, S. H. (2011). The structural organization of human valuesevidence from three rounds of the European Social Survey (ESS). Journal of Cross-Cultural Psychology, 42, 759-776.

Bruns $\varnothing$, K. (1997). Fødevarerelateret livsstil: Udvikling af et måleinstrument til markedsovervågning af forbrugere for fødevareindustrien (Doctoral dissertation, Aarhus School of Business, MAPP Centre).

Bruns $\varnothing$, K., \& Grunert, K. G. (1998). Cross-cultural similarities and differences in shopping for food. Journal of Business Research, 42, 145-150.

Bruns $\varnothing$, K., Scholderer, J., \& Grunert, K. G. (2004a). Closing the gap between values and behavior-a means-end theory of lifestyle. Journal of Business Research, 57, 665-670.

Bruns $\varnothing$, K., Scholderer, J., \& Grunert, K. G. (2004b). Testing relationships between values and food-related lifestyle: results from two European countries. Appetite, 43, 195-205.

Burton, M., Reid, M., Worsley, A. \& Mavondo, F. (2017). Food skills confidence and household gatekeepers' diatary practices. Appetite, 108, 183-190.

Casini, L., Boncinilli, F., Contini, C., Gerini, F., Scozzafava, G., \& Alfnes, F. (2019). Heterogeneous preferences with respect to food preparation time: Foodies and quickies. Food Quality and Preference, 71, 233-241.

Creusen, M., Hultink, E. J., \& Eling, K. (2013). Choice of consumer research methods in the front end of new product development. International Journal of Market Research, 55, 81-104.

Dimitrov, D. M. (2010). Testing for factorial invariance in the context of construct validation. Measurement and Evaluation in Counseling and Development, 43, 121-149.

Grunert, K. G. (2019). International segmentation in the food domain: Issues and approaches. Food research international, 115, 311-318.

Grunert, K. G. (2020). Measuring meaning of food in life. In H. Meiselman (Ed.), Handbook of Eating and Drinking (pp. 1-18). New York: Springer. 
Grunert, K. G., Bruns $\varnothing$, K., Bredahl, L., \& Bech, A. C. (2001). Food-related lifestyle: A segmentation approach to European food consumers. In L. Frewer et al. (Eds.), Food, people and society (pp. 211-230). Berlin, Heidelberg: Springer.

Gutman, J. (1982): A means-end chain model based on consumer categorization processes. Journal of Marketing, 46(2), 60-72.

Kazbare, L., van Trijp, H. C., \& Eskildsen, J. K. (2010). A-priori and post-hoc segmentation in the design of healthy eating campaigns. Journal of Marketing Communications, 16, 21-45.

Kim, S., Lee, K., \& Lee, Y. (2018). Selection attributes of home meal replacements by food-related lifestyles of single-person households in South Korea. Food Quality and Preference, 66, 44-51.

Kubacki, K., Rundle-Thiele, S., Pang, B., Carins, J., Parkinson, J., Fujihira, H., \& Ronto, R. (2017). An umbrella review of the use of segmentation in social marketing interventions. In Segmentation in social marketing (pp. 9-23). Springer, Singapore.

Lombardini, A., Migliore, G., Verneau, F., Schifani, G., \& Cembalo, L. (2015). Are "good guys" more likely to participate in local agriculture? Food Quality and Preference, 45, 158-165.

Pèrez-Cueto, F.J.A., Verbeke, W., de Barcellos, M., D., Kehagia, O., Chryssochoidis, G., Scholderer, J., \& Grunert, K. (2010). Food-related lifestyles and their association to obesity in five European countries. Appetite, 54, 156-162.

Pliner, P \& Hobden, K. (1992). Development of a scale to measure the trait of food neophobia in humans. Appetite,19, 105-120.

Sarti, S., Darnall, N., \& Testa, F. (2018). Market segmentation of consumers based on their actual sustainability and health-related purchases. Journal of Cleaner Production, 192, 270-280.

Scholderer, J., Bruns $\varnothing$, K., Bredahl, L., \& Grunert, K. G. (2004). Cross-cultural validity of the foodrelated lifestyles instrument (FRL) within Western Europe. Appetite, 42, 197-211.

Schwartz, S.H. (1992). Universals in the content and structure of values: theoretical advances and empirical tests in 20 countries. In: Zanna, M.P. (Ed.), Advances in Experimental Social Psychology. Academic Press, San Diego, CA, pp. 1-65.

Steenkamp, J. B. E., \& Baumgartner, H. (1998). Assessing measurement invariance in crossnational consumer research. Journal of Consumer Research, 25, 78-90.

Szakály, Z., Szente, V., Kövér, G., Polereczki, Z, \& Szigeti, O. (2012). The influence of lifestyle on health behaviour and preference for functional foods. Appetite, 58, 406-413. 
Thøgersen, J. (2017). Sustainable food consumption in the nexus between national context and private lifestyle: A multi-level study. Food Quality and Preference, 55, 16-25.

Verain, M. C., Sijtsema, S. J., \& Antonides, G. (2016). Consumer segmentation based on foodcategory attribute importance: The relation with healthiness and sustainability perceptions. Food Quality and Preference, 48, 99-106.

Vermunt, J. K., \& Magidson, J. (2013). Technical guide for Latent GOLD 5.0: Basic, advanced, and syntax. Belmont, MA: Statistical Innovations Inc.

Wedel, M., \& Kamakura, W. A. (2012). Market segmentation: Conceptual and methodological foundations, $2^{\text {nd }}$ ed. New York: Springer Science \& Business Media. 
Figure 1: Modular food-related lifestyle model

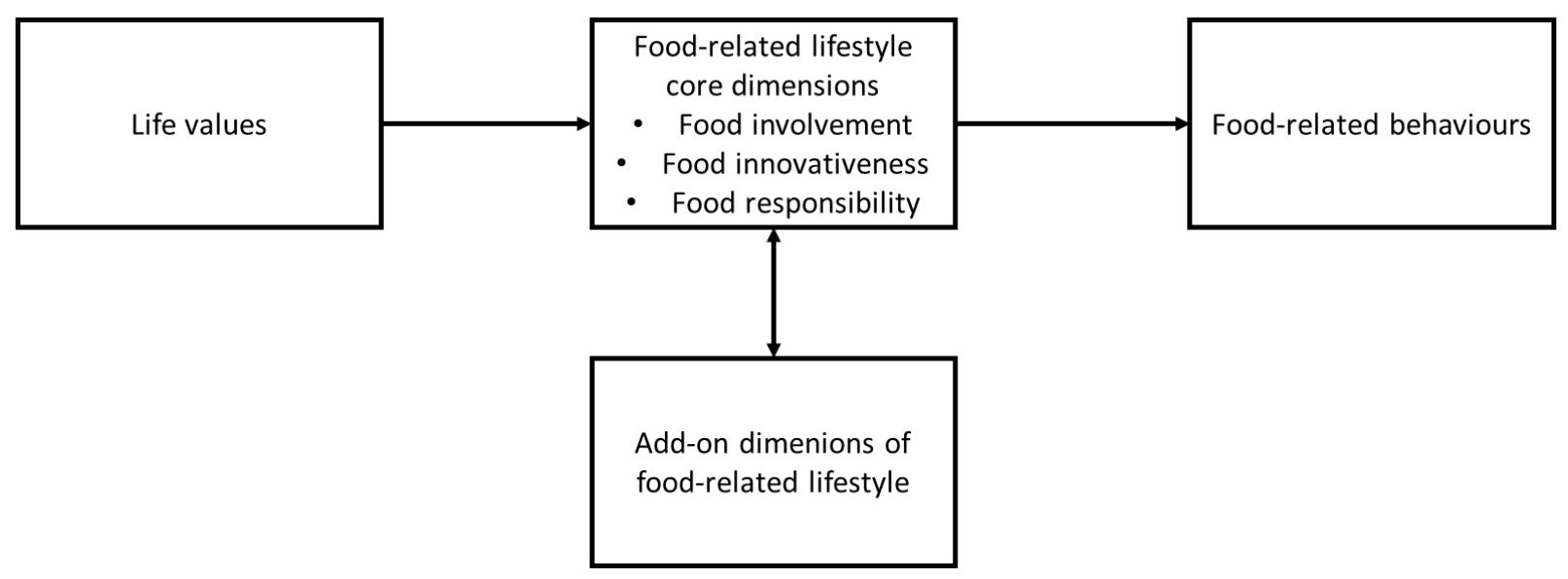


Table 1: Sample characteristics

\begin{tabular}{|c|c|c|c|c|c|c|c|}
\hline & & $\begin{array}{l}\mathrm{DK} \\
(\mathrm{N}=508)\end{array}$ & $\begin{array}{l}A U \\
(N=505)\end{array}$ & $\begin{array}{l}\mathrm{HU} \\
(\mathrm{N}=500)\end{array}$ & $\begin{array}{l}\text { UK } \\
(N=548)\end{array}$ & $\begin{array}{l}\text { USA } \\
(\mathrm{N}=809)\end{array}$ & $\begin{array}{l}\mathrm{NZ} \\
(\mathrm{N}=526)\end{array}$ \\
\hline \multicolumn{8}{|l|}{ Gender } \\
\hline & Female & $49.6 \%$ & $63.4 \%$ & $75 \%$ & $48.6 \%$ & $52.0 \%$ & $55.0 \%$ \\
\hline & Male & $50.4 \%$ & $36.6 \%$ & $25 \%$ & $51.4 \%$ & $48.0 \%$ & $45.0 \%$ \\
\hline \multicolumn{8}{|l|}{ Age } \\
\hline & Under 30 & $19.3 \%$ & $24.2 \%$ & $12.8 \%$ & $12.1 \%$ & $24.5 \%$ & $26.4 \%$ \\
\hline & $30-44$ & $22.0 \%$ & $33.8 \%$ & $30.4 \%$ & $24.7 \%$ & $27.0 \%$ & $23.2 \%$ \\
\hline & $45-59$ & $32.7 \%$ & $30.0 \%$ & $31.8 \%$ & $30.3 \%$ & $27.3 \%$ & $25.1 \%$ \\
\hline & 60 plus & $26.0 \%$ & $12.0 \%$ & $25.0 \%$ & $32.9 \%$ & $21.2 \%$ & $25.3 \%$ \\
\hline \multicolumn{8}{|l|}{ Education } \\
\hline & $\begin{array}{l}\text { Primary and } \\
\text { secondary } \\
\text { school }\end{array}$ & $14.0 \%$ & $35.0 \%$ & $44.6 \%$ & $41.2 \%$ & $24.7 \%$ & $24.4 \%$ \\
\hline & $\begin{array}{l}\text { Technical } \\
\text { certificate }\end{array}$ & $40.9 \%$ & $30.9 \%$ & $35.0 \%$ & $17.9 \%$ & $15.7 \%$ & $25.6 \%$ \\
\hline & $\begin{array}{l}\text { Undergraduate } \\
\text { degree }\end{array}$ & $29.9 \%$ & $20.8 \%$ & - & $28.8 \%$ & $36.2 \%$ & $27.6 \%$ \\
\hline & $\begin{array}{l}\text { Postgraduate } \\
\text { degree }\end{array}$ & $15.2 \%$ & $13.3 \%$ & - & $12.1 \%$ & $23.4 \%$ & $22.4 \%$ \\
\hline & $\begin{array}{l}\text { Undergraduate } \\
\text { and } \\
\text { postgraduate } \\
\text { degree }\end{array}$ & $45.1 \%$ & $34.1 \%$ & $20.4 \%$ & $40.9 \%$ & $59.6 \%$ & $50.0 \%$ \\
\hline \multicolumn{8}{|l|}{$\begin{array}{l}\text { No of } \\
\text { persons in } \\
\text { household }\end{array}$} \\
\hline & 18 years + & 1.71 & 1.94 & 2.10 & 1.90 & 1.87 & 2.11 \\
\hline & $\begin{array}{l}\text { Less than } 18 \\
\text { years }\end{array}$ & 0.42 & 0.89 & 0.60 & 0.53 & 0.59 & 0.71 \\
\hline
\end{tabular}

All respondents had main responsibility for food shopping and preparation in the household. The measure used for education in Hungary did not distinguish between undergraduate and postgraduate degrees, so therefor we have added an extra row where the two categories are combined for all countries. 
Table 2: Cross-cultural measurement invariance and item loadings

\begin{tabular}{|l|l|l|l|l|l|l|l|}
\hline Measurement invariance & Chisquare & df & p value & Chisquare/df & RMSEA & CFI & TLI \\
\hline Model & 2837 & 666 & .000 & 4.26 & .031 & .912 & .917 \\
\hline Configural invariance & 2887 & 690 & .000 & 4.18 & .031 & .911 & .919 \\
\hline Metric invariance & 3285 & 720 & .000 & 4.56 & .033 & .896 & .909 \\
\hline Scalar invariance & 3440 & 732 & .000 & 4.70 & .033 & .890 & .905 \\
\hline $\begin{array}{l}\text { Factor covariance- and } \\
\text { variance invariance }\end{array}$ & 4223 & 762 & .000 & 5.54 & .037 & .860 & .884 \\
\hline Error variance invariance & & & & \\
\hline \multicolumn{7}{|l|}{} \\
Standardized loadings for final model
\end{tabular}


Table 3: Bayesian Information Criterion based on the log-likelihood (BIC-LL) for models with 1-6 country classes and 1-6 clusters

\begin{tabular}{|l|r|r|r|r|r|r|}
\hline & $\begin{array}{l}1 \text { country } \\
\text { class }\end{array}$ & $\begin{array}{l}2 \text { country } \\
\text { classes }\end{array}$ & $\begin{array}{l}3 \text { country } \\
\text { classes }\end{array}$ & $\begin{array}{l}4 \text { country } \\
\text { classes }\end{array}$ & $\begin{array}{l}5 \text { country } \\
\text { classes }\end{array}$ & $\begin{array}{l}6 \text { country } \\
\text { classes }\end{array}$ \\
\hline 1 cluster & 64243 & 64251 & 64259 & 64267 & 64275 & 64283 \\
\hline 2 cluster & 62658 & 62617 & 62630 & 62641 & 62658 & 62674 \\
\hline 3 cluster & 62332 & 62275 & 62287 & 62304 & 62328 & 62349 \\
\hline 4 cluster & 62197 & 62146 & 62142 & 62166 & 62188 & 62231 \\
\hline 5 clusters & 62120 & 61997 & 61960 & 61986 & 62016 & 62067 \\
\hline 6 clusters & 62094 & 62018 & 61962 & 61948 & 62049 & 62028 \\
\hline
\end{tabular}


Table 4: Segmentation solution for 5 segments and 3 country classes

\begin{tabular}{|c|c|c|c|c|c|c|}
\hline \multirow{2}{*}{$\begin{array}{l}\text { Country } \\
\text { groups }\end{array}$} & \multirow[b]{2}{*}{ Segments } & \multicolumn{3}{|c|}{ Means } & \multirow{2}{*}{$\begin{array}{c}\text { Cluster } \\
\text { size }\end{array}$} & \multirow[b]{2}{*}{$\mathrm{N}^{*}$} \\
\hline & & Involvement & Innovation & Responsibility & & \\
\hline \multirow{5}{*}{$\begin{array}{l}\text { Australia, } \\
\text { New } \\
\text { Zealand, } \\
\text { USA }\end{array}$} & Adventurous & 5.79 & 5.45 & 4.90 & $45 \%$ & 820 \\
\hline & Moderate & 4.43 & 4.15 & 4.02 & $38 \%$ & 695 \\
\hline & Conservative & 6.06 & 2.80 & 3.91 & $4 \%$ & 74 \\
\hline & Uninvolved & 3.29 & 2.00 & 2.79 & $4 \%$ & 79 \\
\hline & Foodies & 6.74 & 6.71 & 6.00 & $9 \%$ & 172 \\
\hline \multirow{5}{*}{$\begin{array}{l}\text { Denmark, } \\
\text { UK }\end{array}$} & Adventurous & 5.86 & 5.45 & 4.92 & $36 \%$ & 356 \\
\hline & Moderate & 4.48 & 4.19 & 4.04 & $31 \%$ & 307 \\
\hline & Conservative & 5.94 & 2.95 & 3.84 & $9 \%$ & 91 \\
\hline & Uninvolved & 3.47 & 2.26 & 3.13 & $17 \%$ & 167 \\
\hline & Foodies & 6.75 & 6.68 & 5.67 & $7 \%$ & 74 \\
\hline \multirow[t]{5}{*}{ Hungary } & Adventurous & 5.89 & 5.33 & 4.88 & $32 \%$ & 158 \\
\hline & Moderate & 4.33 & 4.04 & 3.85 & $23 \%$ & 114 \\
\hline & Conservative & 5.74 & 3.10 & 3.73 & $39 \%$ & 195 \\
\hline & Uninvolved & 3.73 & 1.96 & 2.70 & $5 \%$ & 26 \\
\hline & Foodies & 6.77 & 6.80 & 5.83 & $1 \%$ & 7 \\
\hline
\end{tabular}

Involvement, innovation, responsibility: mean of 5 items, range 1-7, higher values indicate more involvement, more innovativeness, more responsibility.

*61 cases could not be classified due to missing data. 
Table 5: Profiling segments by mean scores for Schwartz value domains

\begin{tabular}{|l|c|c|c|c|c|}
\hline \multirow{2}{*}{ Value domains } & \multicolumn{5}{|c|}{ Segments } \\
\cline { 2 - 6 } & Foodies & Moderate & Adventurous & Conservative & Uninvolved \\
\hline Benevolence & 0.56 & 0.63 & 0.63 & 0.70 & 0.70 \\
\hline Universalism & 0.42 & 0.43 & 0.49 & 0.32 & 0.48 \\
\hline Self-direction & $0.47^{\mathrm{a}}$ & $0.29^{\mathrm{a}, \mathrm{b}}$ & $0.41^{\mathrm{b}}$ & $0.30^{\mathrm{a}, \mathrm{b}}$ & $0.18^{\mathrm{b}}$ \\
\hline Stimulation & $0.06^{\mathrm{a}}$ & $-.0 .28^{\mathrm{b}}$ & $-0.13^{\mathrm{b}, \mathrm{c}}$ & $-0.66^{\mathrm{c}}$ & $-0.74^{\mathrm{c}}$ \\
\hline Hedonism & $0.20^{\mathrm{a}}$ & $-0.03^{\mathrm{b}}$ & $0.08^{\mathrm{a}, \mathrm{b}}$ & $0.26^{\mathrm{a}}$ & $-0.11^{\mathrm{b}}$ \\
\hline Achievement & -0.30 & -0.48 & -0.40 & -0.47 & -0.51 \\
\hline Power & -0.90 & -0.75 & -0.82 & -0.75 & -0.69 \\
\hline Security & $0.30^{\mathrm{b}}$ & $0.42^{\mathrm{a}, \mathrm{b}}$ & $0.33^{\mathrm{a}, \mathrm{b}}$ & $0.54^{\mathrm{a}}$ & $0.55^{\mathrm{a}}$ \\
\hline Conformity & $-0.23^{\mathrm{d}}$ & $0.04^{\mathrm{c}}$ & $-0.15^{\mathrm{c}, \mathrm{d}}$ & $0.14^{\mathrm{a}, \mathrm{b}}$ & $0.30^{\mathrm{a}}$ \\
\hline Tradition & $-0.58^{\mathrm{b}}$ & $-0.28^{\mathrm{a}}$ & $-0.43^{\mathrm{a}, \mathrm{b}}$ & $-0.37^{\mathrm{a}, \mathrm{b}}$ & $-0.16^{\mathrm{a}}$ \\
\hline Cluster size \% & $8 \%$ & $33 \%$ & $43 \%$ & $7 \%$ & $9 \%$ \\
\hline $\mathrm{n}$ & 175 & 735 & 943 & 146 & 201 \\
\hline
\end{tabular}

Value scores have been standardized for mean 0 and SD 1 across scores for each respondent.

Different superscripts indicate statistically significant differences between cluster means for the domain, $p<.05$, Scheffe test.

Value data were available only for Denmark, New Zealand, UK and USA samples 
Table 6: Profiling segments by frequency of selected behaviours

\begin{tabular}{|c|c|c|c|c|c|}
\hline \multirow{2}{*}{ Behaviours } & \multicolumn{5}{|c|}{ Segments } \\
\hline & Foodies & Moderate & Adventurous & Conservative & Uninvolved \\
\hline \multicolumn{6}{|l|}{ Shopping } \\
\hline Shop at supermarket & $5.5^{\mathrm{a}}$ & $4.9^{c}$ & $5.2^{b}$ & $4.9^{c}$ & $4.9^{c}$ \\
\hline Shop at convenience store & $3.6^{a, b}$ & $3.4^{\mathrm{b}}$ & $3.5^{\mathrm{b}}$ & $4.0^{\mathrm{a}}$ & $3.4^{\mathrm{b}}$ \\
\hline Shop at cheese shop & $2.8^{\mathrm{a}}$ & $1.9^{c}$ & $2.3^{b}$ & $1.6^{d}$ & $1.4^{\mathrm{d}}$ \\
\hline Shop at butcher & $3.7^{\mathrm{a}}$ & $2.7^{c}$ & $3.2^{\mathrm{b}}$ & $3.2^{b}$ & $2.1^{d}$ \\
\hline Shop at fishmonger & $3.1^{\mathrm{a}}$ & $2.2^{c}$ & $2.6^{\mathrm{b}}$ & $1.8^{\mathrm{c}, \mathrm{d}}$ & $1.5^{d}$ \\
\hline Shop online & $3.2^{\mathrm{a}}$ & $2.3^{c}$ & $2.6^{\mathrm{b}}$ & $1.7^{\mathrm{d}}$ & $1.7^{\mathrm{d}}$ \\
\hline Shop at farmer's market & $3.9^{a}$ & $2.6^{c}$ & $3.4^{\mathrm{b}}$ & $3.1^{\mathrm{b}}$ & $1.8^{\mathrm{d}}$ \\
\hline Shop at farm stand/store & $3.2^{\mathrm{a}}$ & $2.3^{b}$ & $2.9^{a}$ & $2.5^{\mathrm{b}}$ & $1.7^{c}$ \\
\hline Shop at fruit and vegetable store & $4.2^{\mathrm{a}}$ & $3.0^{c}$ & $3.8^{\mathrm{b}}$ & $3.4^{\mathrm{b}}$ & $2.2^{\mathrm{d}}$ \\
\hline Shop at bakery & $4.1^{\mathrm{a}}$ & $3.1^{\mathrm{c}}$ & $3.6^{\mathrm{b}}$ & $3.7^{a, b}$ & $2.7^{d}$ \\
\hline \multicolumn{6}{|l|}{ Cooking } \\
\hline Spend > 1 hour in kitchen weekdays & $5.7^{\mathrm{a}}$ & $4.2^{c}$ & $5.1^{\mathrm{b}}$ & $4.5^{c}$ & $3.1^{d}$ \\
\hline Spend $>1$ hour in kitchen weekends & $5.5^{\mathrm{a}}$ & $4.0^{d}$ & $4.9^{b}$ & $4.5^{c}$ & $3.0^{\mathrm{e}}$ \\
\hline Spend $>1$ hour baking & $4.2^{\mathrm{a}}$ & $3.0^{c}$ & $3.7^{\mathrm{b}}$ & $3.2^{c}$ & $2.1^{d}$ \\
\hline \multicolumn{6}{|l|}{ Eating } \\
\hline Eat bread & $5.8^{b, c}$ & $5.5^{c}$ & $5.7^{b, c}$ & $6.2^{\mathrm{a}}$ & $5.5^{\mathrm{a}, \mathrm{b}}$ \\
\hline Eat fish & $4.7^{\mathrm{a}}$ & $3.9^{c}$ & $4.2^{b}$ & $3.3^{d}$ & $3.5^{d}$ \\
\hline Eat buttery/creamy sauces & $4.4^{\mathrm{a}}$ & $3.8^{\mathrm{b}}$ & $4.1^{\mathrm{a}}$ & $3.4^{c}$ & $3.0^{d}$ \\
\hline Eat lentils/pulses & $4.4^{\mathrm{a}}$ & $3.2^{c}$ & $3.9^{b}$ & $3.6^{\mathrm{b}}$ & $2.5^{d}$ \\
\hline Eat vegetables & $6.4^{\mathrm{a}}$ & $5.6^{c}$ & $6.1^{\mathrm{c}}$ & $5.7^{b}$ & $5.3^{d}$ \\
\hline Drink wine & $4.3^{a}$ & $3.1^{c}$ & $3.7^{\mathrm{b}}$ & $3.0^{c, d}$ & $2.6^{d}$ \\
\hline Eat salad & $5.5^{\mathrm{a}}$ & $4.6^{c}$ & $5.2^{b}$ & $4.4^{b}$ & $4.2^{d}$ \\
\hline Eat fruit & $6.0^{\mathrm{a}}$ & $5.4^{c}$ & $5.9^{a, b}$ & $5.7^{b, c}$ & $5.0^{d}$ \\
\hline Eat red meat & $4.8^{\mathrm{a}}$ & $4.6^{a, b}$ & $4.6^{a, b}$ & $4.3^{b, c}$ & $3.9^{c}$ \\
\hline
\end{tabular}




\begin{tabular}{|c|c|c|c|c|c|}
\hline Eat pizza & $4.0^{\mathrm{a}}$ & $3.7^{\mathrm{b}}$ & $3.9^{a, b}$ & $3.4^{\mathrm{c}}$ & $3.3^{c}$ \\
\hline Eat sweets, desserts, cakes & 4.6 & 4.4 & 4.6 & 4.6 & 4.5 \\
\hline Drink beer, cider & $3.8^{\mathrm{a}}$ & $3.2^{\mathrm{b}, \mathrm{c}}$ & $3.3^{b}$ & $2.8^{c, d}$ & $2.6^{d}$ \\
\hline Drink milk & $4.8^{\mathrm{a}}$ & $4.5^{\mathrm{a}, \mathrm{b}}$ & $4.7^{\mathrm{a}, \mathrm{b}}$ & $4.4^{\mathrm{a}, \mathrm{b}}$ & $4.2^{b}$ \\
\hline \multicolumn{6}{|l|}{ Meals } \\
\hline Eat breakfast at home & $6.2^{\mathrm{a}}$ & $5.4^{\mathrm{b}, \mathrm{c}}$ & $5.8^{b}$ & $5.3^{c}$ & $5.6^{b, c}$ \\
\hline Eat breakfast on the go & $3.3^{\mathrm{a}}$ & $2.7^{b, c}$ & $3.0^{a, b}$ & $2.3^{\mathrm{c}}$ & $1.8^{\mathrm{d}}$ \\
\hline Eat lunch at work & $4.3^{\mathrm{a}}$ & $3.5^{b}$ & $4.2^{\mathrm{a}}$ & $3.4^{b, c}$ & $3.0^{c}$ \\
\hline Eat lunch at home & 5.7 & 5.3 & 5.5 & 5.5 & 5.4 \\
\hline Eat dinner at home & $6.5^{\mathrm{a}}$ & $6.2^{\mathrm{b}}$ & $6.4^{\mathrm{a}, \mathrm{b}}$ & $6.6^{a}$ & $6.5^{a, b}$ \\
\hline Eat dinner in a restaurant & $4.0^{\mathrm{a}}$ & $3.3^{c}$ & $3.6^{\mathrm{b}}$ & $2.5^{d}$ & $2.4^{d}$ \\
\hline Eat snacks on the go & $4.2^{\mathrm{a}}$ & $3.5^{b}$ & $3.7^{a, b}$ & $2.8^{\mathrm{c}}$ & $2.7^{c}$ \\
\hline Eat snacks at home & $5.9^{a}$ & $5.4^{b, c}$ & $5.5^{a, b, c}$ & $5.8^{\mathrm{a}, \mathrm{b}}$ & $5.2^{c}$ \\
\hline Cluster size \% & $8 \%$ & $33 \%$ & $40 \%$ & $11 \%$ & $8 \%$ \\
\hline $\mathrm{n}$ & 253 & 1116 & 1334 & 360 & 272 \\
\hline
\end{tabular}

ANOVA of country groups and cluster on behaviour F-test $p<.001$ for all items

Different superscripts indicate statistically significant differences between cluster means for the domain, $p<.05$, Scheffe test.

Frequency measured by $1=$ never, $2=$ less than every 6 months, 3=1-5 times every 6 months, 4=1-3 times every month, $5=1-2$ times per week, $6=3-4$ times per week, 7=every day or almost every day 